\title{
ARTICLE OPEN Spectroscopic ellipsometry study of thickness and porosity of the alteration layer formed on international simple glass surface in aqueous corrosion conditions
}

\author{
Dien Ngo (iD ${ }^{1}$, Hongshen Liu', Nisha Sheth², Raymond Lopez-Hallman², Nikolas J. Podraza ${ }^{3}$, Marie Collin ${ }^{4}$, Stéphane Gin ${ }^{4}$ and \\ Seong H. Kim (iD)
}

The porosity and pore-size distribution in the glass play an important role in glass corrosion; however, such information is difficult to be obtained non-destructively. Here we report the use of spectroscopic ellipsometry (SE) under controlled humidity environments to determine those structural parameters in the alteration layers formed on international simple glass (ISG), a model nuclear waste glass, in aqueous corrosion conditions. The SE results show that the ISG sample corroded for nearly 4.5 years develops pores larger than $2 \mathrm{~nm}$ in diameter, while the alteration layers formed initially in less than 1 month do not have such large pores. The development of larger pores over a long period of corrosion time, while the overall thickness remains relatively constant, implies structural rearrangements of the silicate network occurring within the alteration layer, which could eventually affect the transport of reactants and products as well as the structural stability.

npj Materials Degradation (2018)2:20; doi:10.1038/s41529-018-0040-7

\section{INTRODUCTION}

Understanding glass corrosion behaviors in aqueous media is important to develop the degradation mechanism of glass materials and predict their environmental stability. ${ }^{1-9}$ Due to ion exchange, hydrolysis-condensation and/or dissolution-reprecipitation, and reconstruction of the glass network during the corrosion process, the composition and structure of the surface region of glass are changed, forming a so-called alteration layer whose structure is different from the bulk. ${ }^{4,10-12}$ The alteration layer is usually rich in silica content and contains hydrous species ( $\mathrm{Si}-\mathrm{OH}$ and $\mathrm{H}_{2} \mathrm{O}$ ) like a hydrated porous gel; this surface layer could work as a molecular sieve to protect the glass from further corrosion. ${ }^{4}$ The properties of water in such layers vary with pore sizes and the amount of water filling the internal pores. ${ }^{13-15}$ Depending on the pore size, the confined water molecules could behave like bulk water or confined water that is interacting with the pore wall. ${ }^{16,17}$ The information on the porosity and pore-size distribution in the alteration layer, therefore, is important to understand the transport of water and other hydrolysis products through the alteration layer and then the mechanism of further corrosion. This structural information is also valuable for computer simulations of glass dissolution and for understanding mechanical properties of altered glass surfaces. ${ }^{16,18}$

In the previous studies, the pore sizes in the gel layer have been estimated using transmission electron microscopy or a postexperiment tracing test. ${ }^{2,4}$ The former is a destructive method and it would be difficult to determine the exact pore-size distribution unless the pores are periodic with clear imaging contrasts. ${ }^{2}$ The latter uses organic dyes or stains with certain molecular sizes that can be traced with another method, such as depth profiling with
X-ray photoelectron spectroscopy (XPS) or time-of-flight secondary ion mass spectrometry (ToF-SIMS). However, diffusion of dye molecules would be extremely slow if the pore size is comparable to the size of the probe molecules. Without knowing the exact structure or chemical composition of the pore surfaces, it would be difficult to estimate the diffusion coefficient of probe molecules in the Knudsen diffusion regime. Thus, it is desirable to measure the pore-size distribution in the alteration layer with a nondestructive and stain-free method.

Spectroscopic ellipsometry (SE) is suitable for that purpose. ${ }^{19-26}$ The float glass corrosion has been investigated by monitoring the changes of ellipsometric angles. ${ }^{22}$ Portal et al. has demonstrated that the corroded layer thicknesses obtained from SE were in good agreement with results obtained from ToF-SIMS in a study of corrosion of an alkali silicate glass. ${ }^{25}$ This study also revealed a porous, layered structure of the corroded surface. ${ }^{25}$ Recently, SE was used to characterize the pore volume fraction and alteration layer thickness of International Simple Glass (ISG) coupons corroded in aqueous solutions of different $\mathrm{pH}$ values with the corroded surface layers modeled by introducing a gradient in refractive index with depth into the altered layer. ${ }^{24}$ Good agreement between the alteration layer thicknesses obtained by $\mathrm{SE}$ and that from scanning electron microscopy (SEM) were obtained. ${ }^{24}$ However, the pore-size distribution in the alteration layer has not been determined.

Here, we demonstrate the use of SE to analyze adsorption and desorption isotherms of water vapor in the alteration layer formed on ISG via aqueous corrosion. ISG, a model system mimicking nuclear waste glass materials, is a boroaluminosilicate glass with sodium and calcium ions as network modifiers and a trace amount

\footnotetext{
${ }^{1}$ Department of Chemical Engineering and Materials Research Institute, The Pennsylvania State University, University Park, PA 16802, USA; ${ }^{2}$ Department of Materials Science and Engineering, The Pennsylvania State University, University Park 16802 , USA; ${ }^{3}$ Department of Physics and Astronomy, The University of Toledo, Toledo, Ohio, USA and ${ }^{4}$ CEA, DEN, DE2D, SEVT, F-30207 Bagnols-sur-Ceze, Bagnols-sur-Ceze, France

Correspondence: Seong H. Kim (shkim@engr.psu.edu)
}

Received: 9 February 2018 Revised: 8 May 2018 Accepted: 10 May 2018

Published online: 04 July 2018 

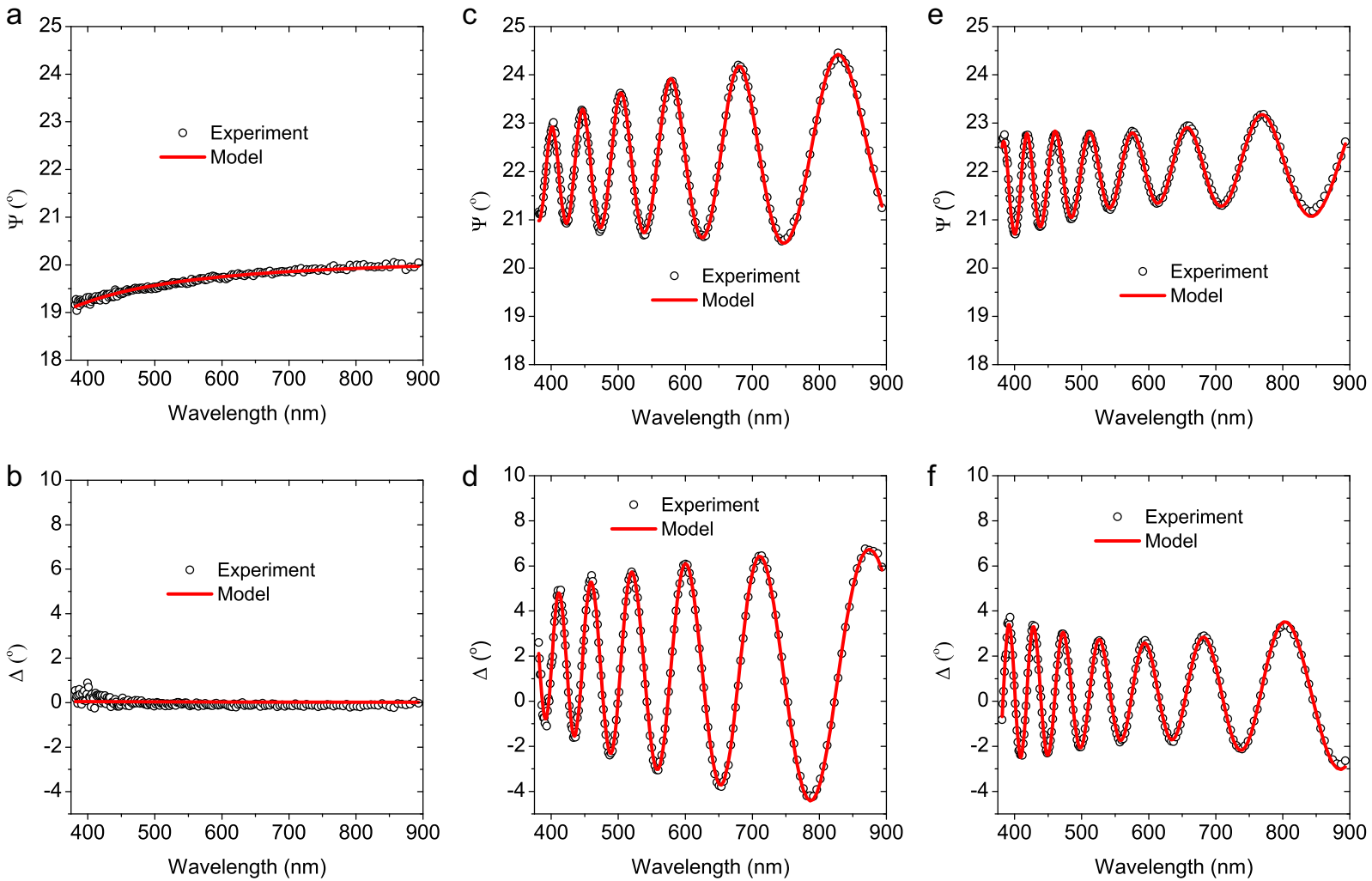

Fig. 1 Experimental ellipsometric spectra (in $\Psi$ and $\Delta$ ) of the ISG coupons measured at $0 \%$ RH. a, b Before corrosion experiment; $\mathbf{c}$, d sample corroded in $\mathrm{SiO}_{2}$-saturated water without $\mathrm{KCl}$ for 7 days; e, f sample corroded in $\mathrm{SiO}_{2}$-saturated water with $40 \mathrm{mM} \mathrm{KCl}$ for 1625 days. The solid lines are fittings to experimental data. The SE incident angle was $70^{\circ}$

of zirconium as an additional network former (composition (mol \%): $\left.60.2 \mathrm{SiO}_{2}, 16.0 \mathrm{~B}_{2} \mathrm{O}_{3}, 12.6 \mathrm{Na}_{2} \mathrm{O}, 3.8 \mathrm{Al}_{2} \mathrm{O}_{3}, 5.7 \mathrm{CaO}, 1.7 \mathrm{ZrO}_{2}\right){ }^{27}$ The ISG coupons were corroded in aqueous solutions of $\mathrm{pH}$ 7 saturated with soluble $\mathrm{SiO}_{2}$-species and varying concentrations of $\mathrm{KCl}(0-40 \mathrm{mM})$ at $90^{\circ} \mathrm{C}$ for 7 days, 28 days, and 1625 days. It is known that in these conditions the corrosion rate is high initially and then diminished due to the formation of a passivating layer. ${ }^{4}$ The period with a high forward reaction rate is called stage-I and the period with a very low residual corrosion rate is called stage-ll. Based on previous studies, ${ }^{28}$ the samples corroded for 7,28 , and 1625 days can be considered as in the stage-ll of glass corrosion process. The analyses of SE spectra obtained provide not only the thickness and refractive index of the alteration layer, but also information on porosity and pore-size distribution in the alteration layer. The changes in the porosity and pore-size distribution over time may provide insights into structural alterations or rearrangements in the silica-rich alteration layer during stage-II of ISG aqueous corrosion.

\section{RESULTS AND DISCUSSION}

Thickness, void volume fraction, and refractive index of corroded layers

Figure. 1, as an example, shows ellipsometric spectra (in $\psi$ and $\Delta$ ) over a spectral range from 381 to $893 \mathrm{~nm}$ for ISG coupons before corrosion experiments, corroded in $\mathrm{SiO}_{2}$-saturated aqueous solution for 7 days, corroded in $\mathrm{SiO}_{2}$-saturated solution containing $40 \mathrm{mM} \mathrm{KCl}$ for 1625 days, respectively. The SE measurements of corroded samples were performed after holding the samples at $0 \% \mathrm{RH}$ inside the environment-controlled sample cell for about $10 \mathrm{~h}$. In this way, all molecular species that can be desorbed without heating are desorbed. Heating the sample, in situ, for further dehydration was not used in this experiment, since it results in collapse and delamination of the alteration layer. Note that further dehydration is possible using a critical point drying method before the SE measurement, ${ }^{24}$ but, the air exposure during the sample transfer to the ellipsometer allows reabsorption of water into the alteration layer (see Figs. 3 and 4 in the next section), annihilating such ex situ drying effect. Interference fringes are observed in the ellipsometric spectra for the corroded samples (Fig. 1c-f), indicating a thick alteration layer with optical response differing from that of the underlying uncorroded glass substrate. The same feature is also present on the ellipsometric spectra of ISG samples corroded in other conditions (see Fig. S1 in Supplementary Information, SI).

The ellipsometric spectra of corroded ISG coupons in this study were fitted with an optical model including four discrete sublayers representing different optical characteristics on a semi-infinite uncorroded glass substrate. Each sublayer has an index of refraction different from those of the other sublayers and the underlying uncorroded bulk. The refractive index of a sublayer is modeled using a Bruggeman effective medium approximation (EMA) accounting for fractions of pristine glass and void at $0 \%$ $\mathrm{RH}^{29}$ At non-zero $\mathrm{RH}$, the contribution due to absorbed water is introduced into the EMA, while the layer thickness and glass volume fraction in each sublayer remain the same as the $0 \% \mathrm{RH}$ values. The data shown in Fig. 1 exhibit a good agreement between the experimental data and the fit generated by this model (see Fig. S1 in SI for other fit results). The optical model could be expanded to more layers or alternately, a continuous gradient in refractive index could be applied. Although the increased degrees of freedom could improve the overall fitting, it would also increase the uncertainty in the physical structure model applied. Thus, all fittings in SE data analysis were limited to the minimum number of layers needed. 

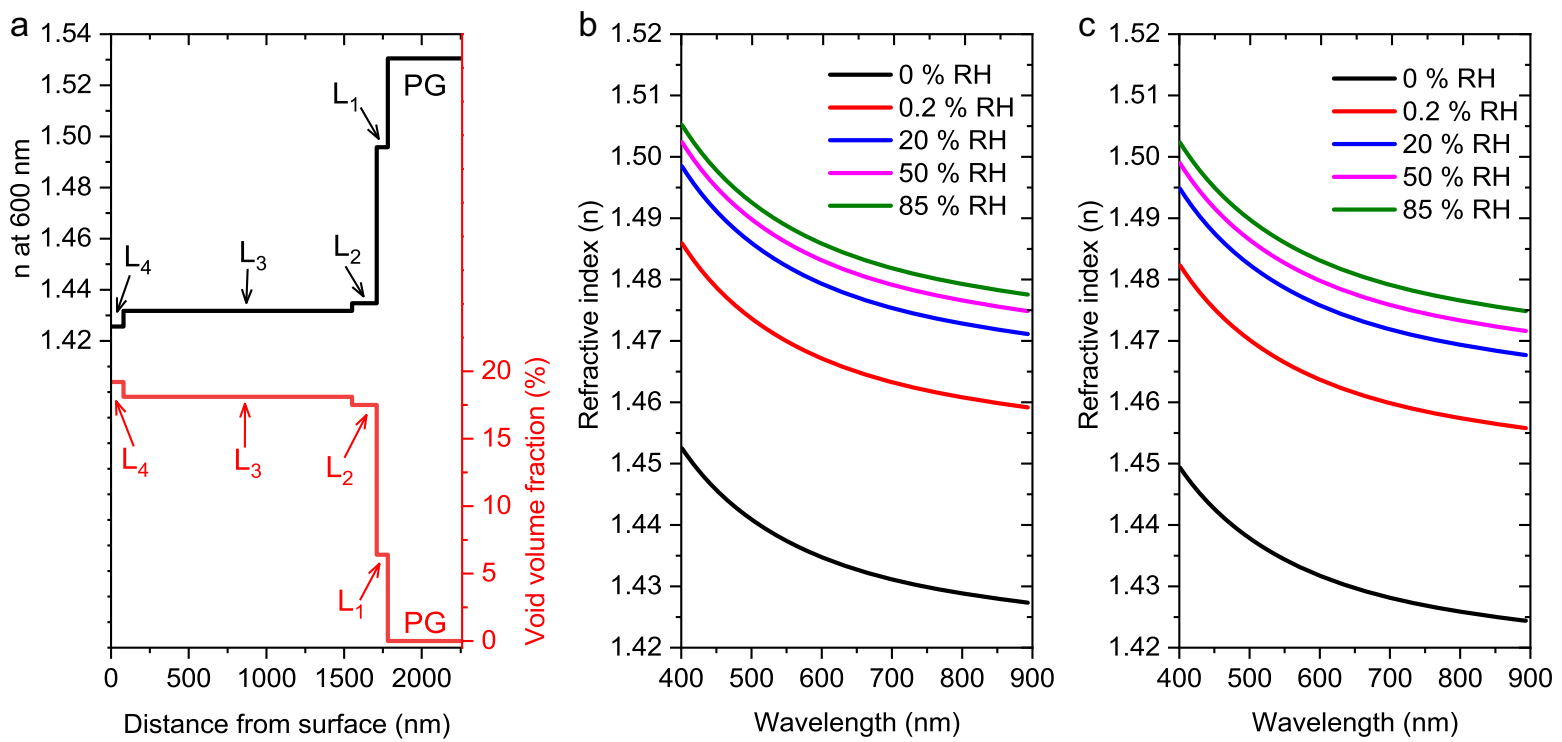

Fig. 2 ISG coupon corroded in $\mathrm{SiO}_{2}$-saturated water for 7 days: a Void volume fraction and refractive index gradients at $0 \% \mathrm{RH}$, $\mathrm{PG}$ is the pristine glass (bulk), and $\mathrm{L}_{1-4}$ are surface layers with distinct refractive index and void volume fraction, respectively; $\boldsymbol{b}$ Refractive index of layer 2 (inter-phase region between the alteration layer and the bulk); c Refractive index of layer 3 (the thickest part in the alteration layer)

The leaching of ISG in silica saturated solution lead to an incongruent dissolution of $\mathrm{B}, \mathrm{Na}$, and $\mathrm{Ca}$ and a partial hydrolysis of the other glass formers ( $\mathrm{Si}, \mathrm{Al}$, and $\mathrm{Zr}$ ). ${ }^{3,4,15}$ The amount of $\mathrm{Ca}$ retained in the gel layer depends on the presence of $\mathrm{K}$ in the solution. ${ }^{30}$ As the glass-to-gel transformation takes place at constant volume, ${ }^{15}$ the loss of the mobile glass cations during aqueous corrosion leads to an increase in pore volume fraction and a decrease in refractive index in the alteration layer. As an example, Fig. 2a shows the void volume fraction and refractive index at a wavelength of $600 \mathrm{~nm}$ as a function of depth from the external surface obtained from the fit of the SE data measured at $0 \% \mathrm{RH}$ for the alteration layer on the ISG sample formed in $\mathrm{SiO}_{2}-$ saturated water without $\mathrm{KCl}$ for seven days. In all cases studied, the void volume fraction increases from $0 \%$ in the bulk to $20 \%$ in the topmost surface region (see Fig. S2 in SI for other data). The step-wise change is an artifact expected for an optical model with four discrete layers. In reality, the trend would be a smooth gradient; thus, the void volume fraction of each layer in Fig. 2a could be viewed as an average value of the region represented by the thickness of each layer.

This change in refractive index with depth can be attributed to a depth dependence on relative void fraction, changes in concentration of leachable elements $(\mathrm{B}, \mathrm{Na})$ in the glass, and density changes due to network reconstruction upon the loss of boron. The void volume fraction of the outer layer (marked as $L_{4}$ in Fig. 2a) is partly due to the roughness of the corroded surface, which have originated from mechanical polishing of the pristine surface. The very thin layer near the pristine bulk (marked as $L_{1}$ in Fig. $2 \mathrm{a}$ ) has the lowest value of void volume fraction and this region is assumed to be the reaction front of the aqueous corrosion process. ${ }^{2}$ The interface between this innermost $L_{1}$ layer and the pristine glass also has a roughness or lateral inhomogeneity due to the stochastic nature of the corrosion process. ${ }^{3}$ Then, the $L_{2}$ and $L_{3}$ layers in Fig. $2 a$ can be called as the interphase region between the alteration layer and the bulk glass and the main part of the alteration layer, respectively.

The refractive indices of the $L_{2}$ and $L_{3}$ sublayers in the alteration layer of the sample formed in $\mathrm{SiO}_{2}$-saturated water without $\mathrm{KCl}$ for seven days are given in Fig. $2 b$, c. The refractive index spectra were determined at different relative humidities. The increase in the refractive index upon an increase in $\mathrm{RH}$ suggests that the alteration layers are porous and those pores are readily accessible

\begin{tabular}{|c|c|c|}
\hline $\begin{array}{l}\text { Experimental } \\
\text { conditions }\end{array}$ & $\begin{array}{l}\text { Thickness by SE } \\
(\mathrm{nm})\end{array}$ & $\begin{array}{l}\text { Thickness by XPS or ToF-SIMS } \\
(\mathrm{nm})\end{array}$ \\
\hline $0 \mathrm{mM} \mathrm{KCl}, 7$ days & $1782 \pm 22$ & 1960 \\
\hline $13 \mathrm{mM} \mathrm{KCl}, 7$ days & $1304 \pm 25$ & 1500 \\
\hline $13 \mathrm{mM} \mathrm{KCl}, 28$ days & $2376 \pm 6$ & 2250 \\
\hline $\begin{array}{l}40 \mathrm{mM} \mathrm{KCl} \\
1625 \text { days }\end{array}$ & $1995 \pm 18$ & 1800 \\
\hline \multicolumn{3}{|c|}{$\begin{array}{l}\text { All aqueous solutions in corrosion experiments were at } \mathrm{pH} 7,90^{\circ} \mathrm{C} \text { and } \\
\text { saturated with soluble } \mathrm{SiO}_{2} \text { species. The experimental conditions that } \\
\text { reflect the differences between corrosion solutions are shown in the first } \\
\text { column of the table. The SE fit results are shown in Supplementary } \\
\text { Information; the SE thickness is the sum of all four layers }\left(\mathrm{L}_{1}+\mathrm{L}_{2}+\mathrm{L}_{3}+\mathrm{L}_{4}\right) \text {. } \\
\text { To compare with the } \mathrm{SE} \text { thickness the alteration layer thickness of the } 1625 \\
\text { day-corroded sample was determined from depth profiling with ToF-SIMS, } \\
\text { while those of other samples were from depth profiling with XPS. }\end{array}$} \\
\hline
\end{tabular}

by water molecules in the gas phase. It is important to keep in mind that holding the sample in $0 \% \mathrm{RH}$ at $22^{\circ} \mathrm{C}$ could not remove all strongly bound water molecules. The strongly bound water could be removed by heating the sample to a temperature higher than $300^{\circ} \mathrm{C}$, but such heating could cause the collapse and delamination of the alteration layers due to the difference in thermal expansion coefficients between the alteration layer and the bulk pristine glass and/or the capillary force of water meniscus inside pores. On a flat surface, the capillary force is largest at $\mathrm{RH}$ around $10-20 \% .^{31}$ Since the alteration layer is stable upon cycling $\mathrm{RH}$ below and above this range, the capillary force effect appears insignificant at least in the ambient conditions.

The total thicknesses of alteration layers from the SE analysis of ISG coupons subjected to different corrosion conditions are given in Table 1. For a comparison, the alteration layer thicknesses determined from XPS or ToF-SIMS depth profiling are also provided. The uncertainties in XPS and ToF-SIMS depth profiling are $10 \%$ and $5 \%$, respectively. The results show comparable values of the corroded layer thickness obtained by different techniques. The presence of $\mathrm{KCl}$ in aqueous solutions appears to reduce the growth rate of corrosion layers of ISG coupons in comparison to 


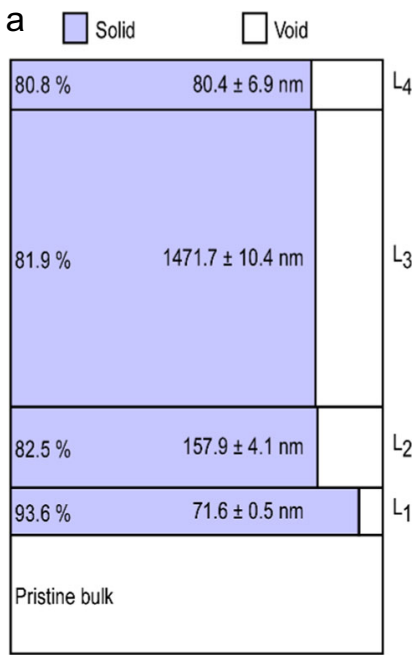

b

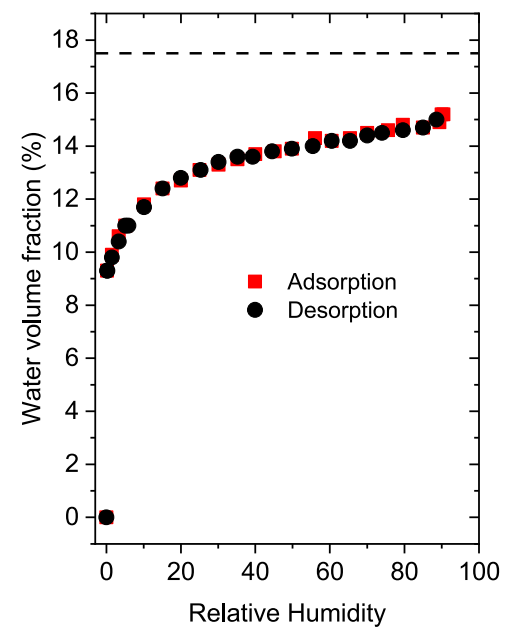

C

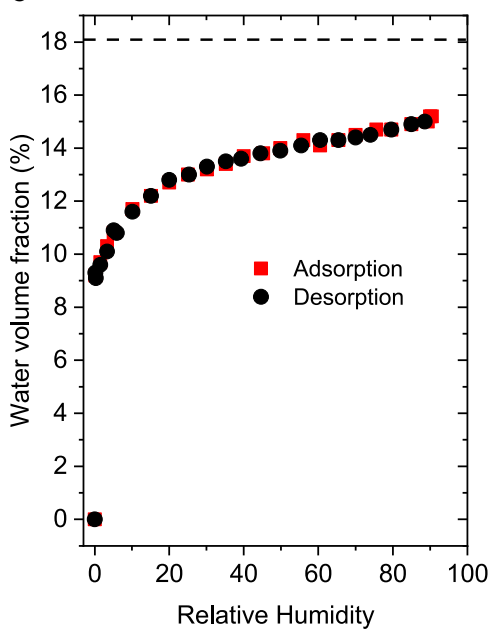

Fig. 3 ISG coupon altered in $\mathrm{SiO}_{2}$-saturated water without $\mathrm{KCl}$ for 7 days: a Optical model of the sample at $0 \% \mathrm{RH}\left(\mathrm{L}_{1-4}\right.$ are surface layers); $\mathbf{b}$ Isotherm of water in layer 2 (deeper region close to the bulk); $\mathbf{c}$ Isotherm of water in layer 3 (thick middle region). The dashed lines in (b,c) are the void fraction determined by fitting the SE data at $\mathrm{RH}=0 \%$

that in pure water. In the presence of an electrolyte in the aqueous solution, cations can diffuse into the alteration layer during the corrosion process (see Table S2 in SI). Those cations might reduce or hamper the transport of water molecules in the alteration layer or alter reaction dynamics at the interface with the pristine bulk glass. It has been reported that for a mixture of $\mathrm{H}_{2} \mathrm{O}-\mathrm{CaCl}_{2}$ confined in Vycor, the local diffusion coefficient of confined water molecules was only $6 \%$ of the value of pure water confined in vycor. $^{32}$ The slower diffusion of confined water in the alteration layer during the aqueous corrosion process could have significant impacts on the overall rate of corrosion. ${ }^{12}$

The effects of $\mathrm{K}^{+}$and other alkaline ions on the alteration kinetics of ISG glass have been studied by Collin et al. in similar conditions as those of the present study $\left(90^{\circ} \mathrm{C}, \mathrm{pH} 7\right.$, and silica saturated solution). ${ }^{30}$ The $\mathrm{K}^{+}$was shown to decrease glass alteration rate. The study also showed that the effects of $\mathrm{K}^{+}, \mathrm{Na}^{+}$, and $\mathrm{Li}^{+}$are different. Under the experimental conditions of the study, the pore wall is negatively charged by the dissociation of silanol groups and the charged surface induces an ordered structure of surface water. While the effective ionic radii of the cations clearly influences the interaction between the hydrated ions and gel surface, the electrostatic interactions between these hydrated ions and pore wall need to be considered for a better understanding of the obtained results. ${ }^{33,34}$ Due to the charge of the pore surface, water in the pore will act as confined or bulk-like molecule depending on pore sizes; thus, the dynamics of water will be affected. The effects of alkaline ions on water structure at charged interfaces have been observed for open systems $s^{33,34}$ and they might be different in confined geometry like nanoporous gel layer.

\section{Adsorption-desorption isotherms}

The refractive index change of the alteration layers with ambient $\mathrm{RH}$ condition implies that the layers are porous (Fig. 2). To further characterize the pore sizes, adsorption-desorption measurements of water were performed using SE while RH was changed stepwise from 0 to $\sim 90 \%$ then back to $0 \%$. If the adsorption isotherm shows a type-IV behavior, then the pore-size distribution can be obtained using the Kelvin equation. ${ }^{35}$ It is also possible to obtain information about the affinity between the pore surfaces and the water adsorbate. ${ }^{36}$ The analysis of ellipsometric spectra collected at $0 \% \mathrm{RH}$ were used to determine the initial solid and void volume fractions within each sublayer in addition to each sublayer thickness. During the isotherm measurements, the solid volume fractions and thicknesses were assumed to be constant and the water molecules filled the open pore in the layers.

The optical models obtained from SE data of $0 \% \mathrm{RH}$ for ISG coupons corroded in aqueous solutions without and with $13 \mathrm{mM}$ $\mathrm{KCl}$ for seven days and with $40 \mathrm{mM} \mathrm{KCl}$ for 1625 days are presented in Figs. 3-5 with their corresponding adsorption-desorption isotherms of water in the $L_{2}$ and $L_{3}$ sublayers. The optical model and isotherms for the sample altered in $13 \mathrm{mM} \mathrm{KCl}$ solution for 28 days are given in Fig. S3 in SI. The isotherms are given for layers 2 and 3 only in Figs. 3-5. The outer layers $\left(L_{4}\right)$ contain surface roughness so that the isotherms of water in these layers do not completely represent the molecules filling in or evaporating from pores. Thus, the isotherms for this layer were not analyzed to obtain information about pore size. In the case of the $L_{1}$ region, the adsorption-desorption isotherms (see Fig. S4 in SI) show abnormal changes and they might be due to errors in spectral fitting due to the low void volume fraction of this layer or the structural inhomogeneity in the reaction front region between the alteration layer and the pristine bulk.

The water adsorption-desorption isotherms of the alteration layers on ISG coupons corroded for 7 days and 28 days show a type-I isotherm that is typical for porous materials with pore diameters of less than $2 \mathrm{~nm}^{35}$ The isotherms in Figs. 3-5 reveal a strong uptake of water upon increasing $\mathrm{RH}$ from 0 to $\sim 1 \%$. The large slope of these isotherms indicates a strong interaction or affinity between the pore surface and adsorbate (water) molecule. ${ }^{35}$ The water does not fill the entire pores completely at $\mathrm{RH} \sim 90 \%$ (near saturation vapor pressure). It might imply that some pores are not accessible to the water molecules from the gas phase and this is consistent with results obtained in a recent study by Collin et al. ${ }^{30}$

The adsorption-desorption isotherms of water in $L_{2}$ and $L_{3}$ of the ISG coupon corroded for 1625 days (Fig. 5b, c) show a type-IV isotherm with hysteresis loops at RH between 30 and $60 \%$. These hystereses are due to capillary condensation in large pores with diameters of more than $2 \mathrm{~nm}$. A strong uptake of water at low $\mathrm{RH}$, however, indicates that pore diameters of less than $2 \mathrm{~nm}$ are also present in the corroded layer. Such behavior is not observed for the alteration layer formed in 7 and 28 days. Specular reflection infrared (SR-IR) spectroscopy analysis shows no drastic differences in the silicate network of the alteration layers among four samples prepared in this study (see Fig. S5 in SI). Combining SR-IR and SE data together, it can be inferred that the local network 
a

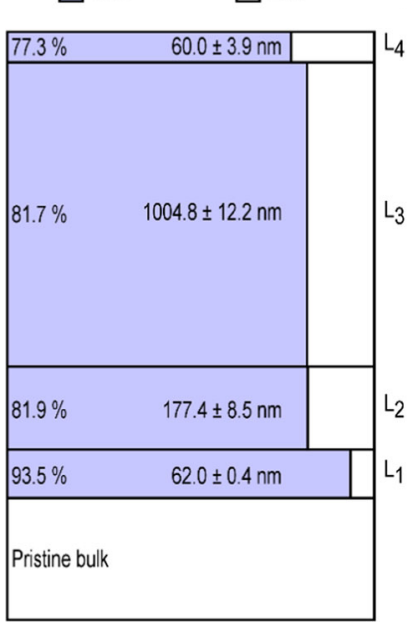

b

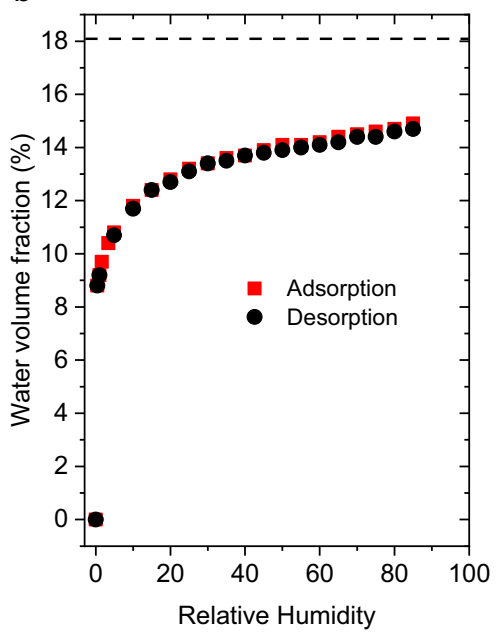

C

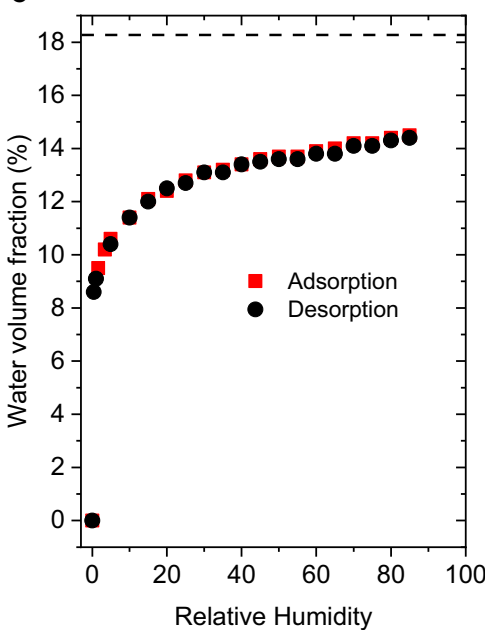

Fig. 4 ISG coupon altered in $\mathrm{SiO}_{2}$-saturated solution with $13 \mathrm{mM} \mathrm{KCl}$ for 7 days: a Optical model of the sample at $0 \% \mathrm{RH}\left(\mathrm{L}_{1-4}\right.$ are surface layers); $\mathbf{b}$ Isotherm of water in $\mathrm{L}_{2}$ (deeper region close to the bulk); $\mathbf{c}$ Isotherm of water in $\mathrm{L}_{3}$ (thick middle region). The dashed lines in (b,c) are the void fraction determined by fitting the $\mathrm{SE}$ data at $\mathrm{RH}=0 \%$
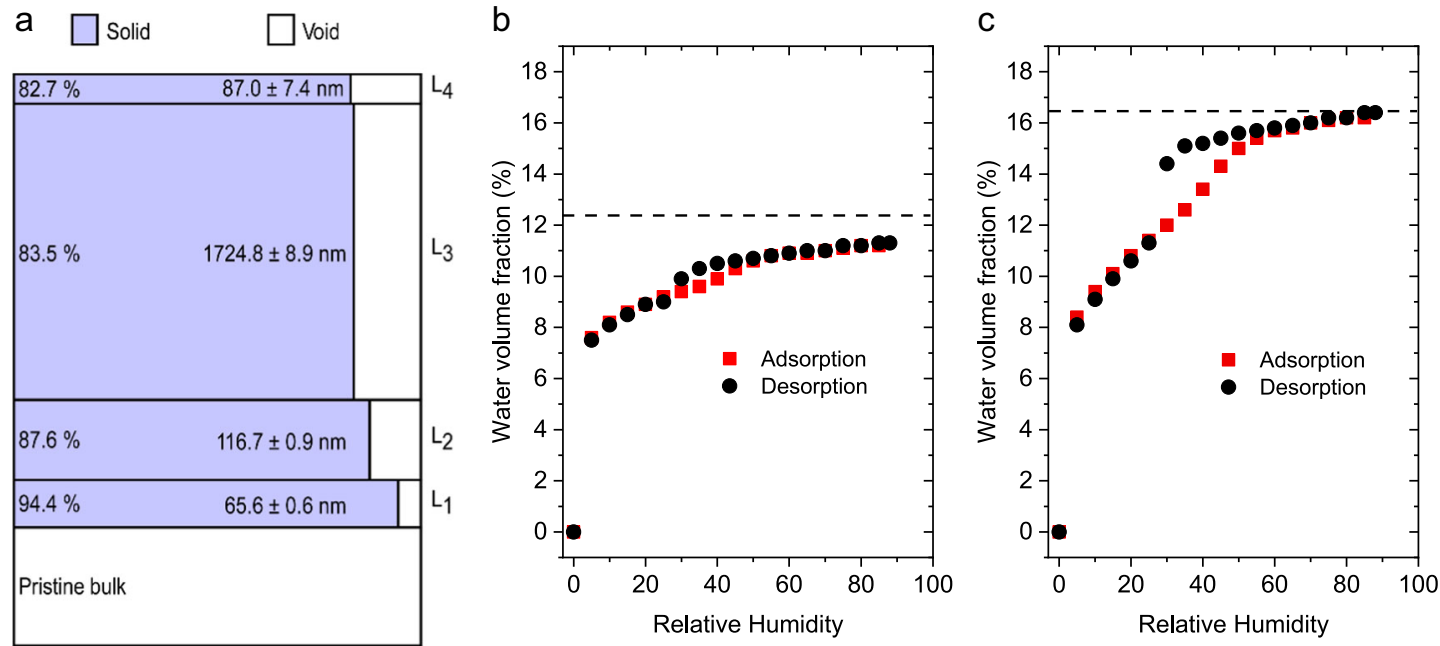

Fig. 5 ISG coupon altered in $\mathrm{SiO}_{2}$-saturated solution with $40 \mathrm{mM} \mathrm{KCl}$ for 1625 days: a Optical model of the sample at $0 \% \mathrm{RH}$ ( $\mathrm{L}_{1-4}$ are surface layers); $\mathbf{b}$ Isotherm of water in layer 2 (deeper region close to the bulk); $\mathbf{c}$ Isotherm of water in layer 3 (thick middle region). The dashed lines in $(\mathbf{b}, \mathbf{c})$ are the void fraction determined by fitting the $\mathrm{SE}$ data at $\mathrm{RH}=0 \%$

connectivity in the alteration layer does not change substantially at the molecular length scale that can be probed by SR-IR during the stage-II period; however, there seems to be network reconstruction processes over a larger length scale occurring over several years, which leads to formation of large pores that did not exist at the inception of stage-ll.

The void volume fractions (or "free" volumes) in the alteration layer of all ISG coupons in the current study are smaller than values obtained in other studies on similar samples. ${ }^{15,24}$ It should be noted that the void volume fractions in this study were determined after holding the samples at $0 \% \mathrm{RH}$ while other studies used different methods such as supercritical $\mathrm{CO}_{2}$ drying ${ }^{24}$ and thermogravimetric analysis (TGA). ${ }^{15}$ It is very difficult to remove strongly bound water in pores at $0 \% \mathrm{RH}$ at ambient temperature; thus, some water may still remain in the corroded layer, especially if there are any closed pores. The supercritical $\mathrm{CO}_{2}$ drying may remove more water from the leached layer, but it will require a special cell for in situ adsorption-desorption experiments with SE without exposing the sample to air after the supercritical $\mathrm{CO}_{2}$ drying. The SE data measured in ambient air after supercritical drying ${ }^{24}$ should be analyzed with a model that considers re-absorption of water from the ambient air, as shown in Fig. 5. The TGA method is destructive and only information about void volume fractions can be obtained. In the TGA method the sample was heated to temperature above $300^{\circ} \mathrm{C}$ so that strongly bounded water can be removed from the leached layer. It should also be noted that this temperature is high enough to induce dehydroxylation reactions of adjacent hydroxyl groups. ${ }^{37}$ As a result, the void volume fraction obtained from TGA measurement is higher than that in the current study.

Pore-size distribution in the alteration layer of the 1625-day corroded ISG sample

The size of pores in the alteration layer of the 1625-day corroded sample was calculated using the Kelvin equation (see Methods). The isotherms in the relative humidity range of $20-90 \%$ were used 

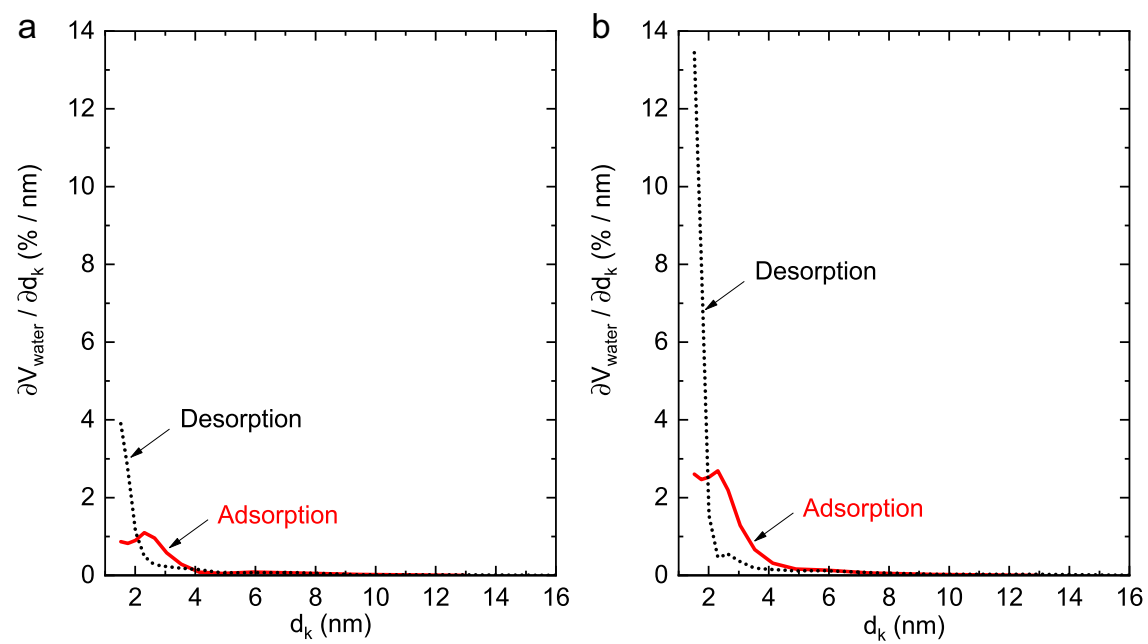

Fig. 6 ISG coupon corroded in $\mathrm{SiO}_{2}$-saturated solution with $40 \mathrm{mM} \mathrm{KCl}$ solution for 1625 days: a Pore-size distribution in $\mathrm{L}_{2}$ (deeper region close to the bulk); $\mathbf{b}$ Pore-size distribution in $\mathrm{L}_{3}$ (thick middle region). The pore-size distributions in each layer were calculated using both adsorption and desorption data

and the pore-size distributions were determined using both adsorption and desorption curves. Due to the lack of information on the network structure of the gel layer it is not determined in this study which branch of the hysteresis loop should be used for the calculation of pore-size distribution. The results are shown in Fig. 6. It should be noted that the calculation result from the Kelvin equation is not the absolute distribution; it is rather a semiquantitative analysis within the validity of the assumptions used in the calculation such as the shape of pores (assumed to be cylindrical in our calculation), surface tension and density of the confined water (assumed to be the same as the bulk values of water), etc. ${ }^{35}$ The distributions in Fig. 6 show that the alteration layers formed on ISG in $\mathrm{SiO}_{2}$-saturated solution with $40 \mathrm{mM} \mathrm{KCl}$ for 1625 days have pores larger than $2 \mathrm{~nm}$ in diameter. In Fig. 6 the $L_{3}$ region has more pores with larger diameters than the $L_{2}$ region. This is reasonable since $L_{3}$ has void volume fraction larger than $L_{2}$ (Fig. 5a). The distribution of pore diameter of less than $2 \mathrm{~nm}$ could not be resolved in this study because it requires more precise control of $\mathrm{RH}$ in the $0-10 \%$ range.

It is known that the presence of the alteration layer on ISG keeps the corrosion rate extremely low, which is designated as the stage-II in the corrosion step (also called residual rate regime). ${ }^{4}$ Although it has not been seen for this glass even after 14 years of alteration, ${ }^{38}$ in some cases after a long period of stage-II, the corrosion rate can suddenly increases again close to the forward reaction rate of stage-l; this resumption of fast corrosion is called stage-III. ${ }^{39,40}$ The causes for the transition from stage-II to stage-III are not fully understood yet. ${ }^{39,41,42}$ It has been shown that the resumption of fast corrosion is often associated with zeolite precipitation and this process is highly dependent on temperature and $\mathrm{pH}$ of the solution. ${ }^{39,40}$ One may add another hypothesis based on the results of pore-size distribution from SE analysis of the alteration layer itself. The large pores growing slowly over time may reduce the mechanical stability or integrity of the alteration layer. If so, the reduced stability may play a role in stage-III. This is a hypothesis that needs to be tested through an independent study.

Comparison of SE and ToF-SIMS depth profiles of the 1625-day old alteration layer

Figure. 7 compares the depth profiles of the alteration layer for the 1625-day ISG sample obtained by ToF-SIMS and SE experiments. The ToF-SIMS profiles are shown for $\mathrm{B}, \mathrm{Na}$, and $\mathrm{Ca}$, while the results of $\mathrm{SE}$ analysis at $0 \% \mathrm{RH}$ profile are the refractive index,
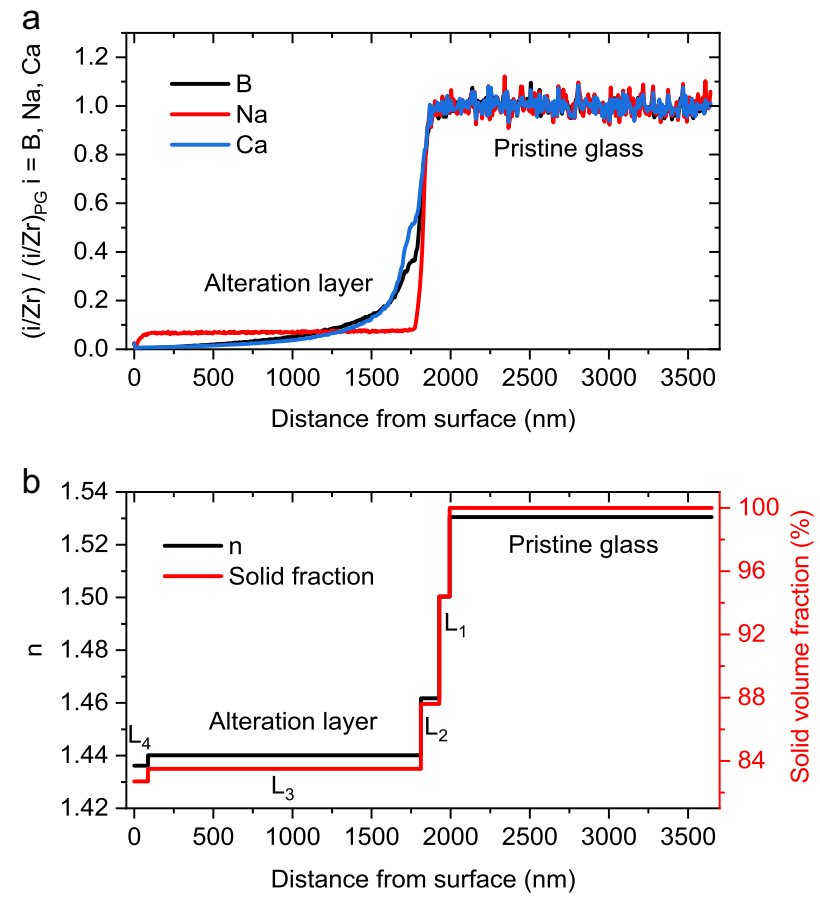

Fig. 7 ISG coupon altered in $40 \mathrm{mM} \mathrm{KCl}$ solution for 1625 days: a ToF-SIMS profiles of $\mathrm{B}, \mathrm{Na}$, and $\mathrm{Ca}$; $\mathrm{B}$ SE profile at $0 \% \mathrm{RH}$ of refractive index at $600 \mathrm{~nm}$ wavelength. $L_{1-4}$ are layers $1-4$, respectively

shown here at a wavelength of $600 \mathrm{~nm}$, and the solid volume fraction. The inter-phase regions where the $\mathrm{Na}, \mathrm{Ca}$, and $\mathrm{B}$ concentrations change drastically in the ToF-SIMS profile could correspond to the $L_{1}$ and $L_{2}$ layers with different solid volume fractions. Especially, the region about $1.8 \mu \mathrm{m}$ from the surface where the slopes of the $\mathrm{Na}$ and $\mathrm{Ca}$ concentration gradients change substantially might correspond to the $L_{2}$ layer. Although the SE profile is stepwise, it could be smoothened by fitting SE spectra with a model including more sublayers in the alteration layer. The structural change in the outer region between $100 \mathrm{~nm}$ and $1.75 \mu \mathrm{m}$ from the surface seems to be insignificant, which can be fitted with a fixed value of refractive index and porosity $\left(L_{3}\right.$ layer in the SE profile). Based on the isotherm data (Fig. 6), the 
Table 2. Experimental conditions of ISG coupons in the present study

\begin{tabular}{llll}
\hline Sample No. & Solution & Temperature $\left({ }^{\circ} \mathrm{C}\right)$ & Corrosion time $($ days $)$ \\
\hline 1 & $\mathrm{SiO}_{2}$-saturated, $0 \mathrm{mM} \mathrm{KCl}$ & 90 & 7 \\
2 & $\mathrm{SiO}_{2}$-saturated, $13 \mathrm{mM} \mathrm{KCl}$ & 90 & 7 \\
3 & $\mathrm{SiO}_{2}$-saturated, $13 \mathrm{mM} \mathrm{KCl}$ & 90 & 28 \\
4 & $\mathrm{SiO}_{2}$-saturated, $40 \mathrm{mM} \mathrm{KCl}$ & 90 & 1625 \\
\hline The $\mathrm{pH}$ of all leaching solutions was $7 \pm 0.5$. & & \\
\hline
\end{tabular}

inter-phase region $\left(L_{2}\right)$ has a lower population of $2-3 \mathrm{~nm}$ wide pores than the outer region $\left(L_{3}\right)$ of the alteration layer.

In summary, SE has been successfully used to characterize the thickness, porosity, and pore-size distribution of the alteration layer on ISG coupons corroded in different experimental conditions. The obtained results show that during the corrosion process, gradients of void volume fraction and refractive index evolve in the glass surface. The thickness of corroded layer is in agreement with the depth profiles obtained with XPS and ToF-SIMS. The water uptake by the alteration layer follows the type-I isotherm for ISG samples corroded for 7 days and 28 days, while it shows the type-IV isotherm for the sample corroded for 1625 days. These results indicate that pore diameters in samples corroded for 7 days and 28 days are less than $2 \mathrm{~nm}$ (below which RH-controlled SE experiment is not very sensitive). The sample corroded for 1625 days contains pores larger than $2 \mathrm{~nm}$, which may imply that silicate network restructuring occurs slowly over a long period of time in the stage-III.

\section{METHODS}

Sample preparation

The samples used in adsorption-desorption SE experiments were corroded in aqueous solutions with or without added electrolyte (Table 2). Before corrosion experiments, ISG coupons $(1 \mathrm{~cm} \times 1 \mathrm{~cm} \times 0.2 \mathrm{~cm})$ were cut from an ISG block (MoSci Corp.). One side of the cut sample was ground and polished to 1 micron surface finish using alumina polishing pads (Allied High Tech Products Inc) and diamond paste (Pace Technologies). The opposite side was not polished to avoid backside reflections in the SE measurements. The samples were then cleaned thoroughly with acetone (Honeywell Burdick \& Jackson) and treated in a UV-Ozone chamber for at least $20 \mathrm{~min}$. The cleaned glass samples were immersed in leaching solutions saturated with silica $\left[\mathrm{C}_{\mathrm{o}}(\mathrm{Si})=143 \mathrm{mg} \mathrm{L}^{-1}\right.$ at $\mathrm{pH} 7$ and $\left.90^{\circ} \mathrm{C}\right]$ in $500 \mathrm{~mL}$ PFA jars (Savillex Corporation). The glass-surface-area-to-solution-volume ratio $(\mathrm{S} N)$ was $0.8 \mathrm{~m}^{-1}$. Experiments were performed in an oven heated to $90^{\circ} \mathrm{C}$ and the $\mathrm{pH}$ of leaching solutions was kept at $7.0 \pm 0.5$ using $0.5 \mathrm{M} \mathrm{HNO}_{3}$ (Alfa Aesar) and $0.5 \mathrm{M} \mathrm{KOH}$ (MACRON Fine Chemicals). There were four samples used in this study. The samples were corroded for 7 days, 28 days, and 1625 days at $90{ }^{\circ} \mathrm{C}$ in $\mathrm{SiO}_{2}$-saturated aqueous solutions containing $[\mathrm{KCl}]=0-40 \mathrm{mM}$. After removal from solution, ISG samples were rinsed thoroughly with ultrapure water $(18 \mathrm{M} \Omega \cdot \mathrm{cm}$ resistivity) and dried under a nitrogen flow from a spraying gun to remove external surface water.

\section{Spectroscopic ellipsometry}

The theoretical background and data analysis methods of SE are described elsewhere. ${ }^{43}$ In an ellipsometry measurement, the change in the polarization state of light is represented by the ratio $(\rho)$ of reflection coefficients for electric field components of light parallel and perpendicular to the plane of incidence.

$\rho=\frac{r_{p}}{r_{\mathrm{s}}}=\tan \psi e^{i \Delta}$

The ratio is a complex value and $\psi$ and $\Delta$ are ellipsometric angles. In ellipsometry, information about the system under the study is obtained by fitting measured ellipsometric spectra to optical and structural models.

The current study used a rotating analyzer spectroscopic ellipsometer (J. A. Woollam Co. Alpha-SE) for optical characterization of corroded ISG glass samples. This ellipsometer configuration had a wavelength range of $381-893 \mathrm{~nm}$ with a step of about $6 \mathrm{~nm}$ wavelength increment and measured $\tan \psi$ and $\cos \Delta$. The incident angle of light used in the study was $70^{\circ}$. The samples were in a cell connected to a humidity control system. The cell had two $\mathrm{CaF}_{2}$ windows that were aligned perpendicular to the incident and reflected light respectively. The humid vapor in the cell was obtained by mixing dry air and $\mathrm{H}_{2} \mathrm{O}$-saturated air that was passed through a jar containing ultrapure water. The total flow rate in all measurements was $2 \mathrm{~L} / \mathrm{min}$. The SE measurements were performed for both adsorption and desorption cycles. During the experiment, each RH was held for at least $30 \mathrm{~min}$. The use of vapor flow allows a fast equilibrium to be reached. ${ }^{44}$ The temperature in the SE cell was about $22^{\circ} \mathrm{C}$ during the experiment.

\section{SE data analysis}

The SE spectra in this study were analyzed using the CompleteEASE software package (J. A. Woollam Co.). The sample was kept at $0 \% \mathrm{RH}$ for about $10 \mathrm{~h}$ before adsorption measurements and ellipsometric spectra at $0 \% \mathrm{RH}$ was analyzed to determine the initial void and solid volume fractions as well as the thickness of sublayers. The corroded glass samples were analyzed using multilayer optical models and the Bruggeman EMA was used in modeling the optical response of each sublayer in the alteration layer. ${ }^{29}$ The general equation for EMA is given in Equation (2), in which $\varepsilon$ is the effective dielectric function of the layer, $f_{i}$ and $\varepsilon_{i}$ are the volume fraction and dielectric function of constituent $i$, respectively.

$\sum_{i=0}^{N} f_{i} \frac{\varepsilon_{i}-\varepsilon}{\varepsilon_{i}+2 \varepsilon}$

For non-absorbing spectral regions, the refractive index is related to the dielectric function via $n^{2}=\varepsilon$. Three pristine bulk glass substrates were first measured and modeled assuming a surface roughness layer represented by an EMA consisting of $50 \%$ glass and $50 \%$ void. ${ }^{43}$ Spectra in $\varepsilon$ are modeled using a combination of a constant additive term equal to unity and a Sellmeier oscillator. ${ }^{45}$

$\varepsilon=1+\frac{A_{\text {High }}}{E_{\text {High }}^{2}-E^{2}}$

where $E_{\text {High }}=9.91 \pm 0.06 \mathrm{eV}$ and $A_{\text {High }}=124.60 \pm 1.72 \mathrm{eV}^{2}$. Least squares regression is used to minimize the weighted mean square error (MSE) between the measured spectra and model fit. ${ }^{46}$ The index of refraction obtained is in agreement with the ones obtained using a prism coupler (Metricon, Model 2010/M; see Fig. S7 in SI) and is used as a reference set of optical properties for the pristine glass in the corroded samples.

In the fitting of SE spectra measured at other relative humidity, the solid volume fraction and the thickness of each sublayer were kept constant while the water volume fraction was varied. The water volume fractions were then plotted versus relative humidity to obtain the adsorption and desorption isotherms.

In the SE analysis of corroded glass samples, some simplifying assumptions were utilized. The boundaries between sublayers were assumed to be parallel, homogenous, and optically isotropic. It was also assumed that there were no changes in pore network and layer thickness during adsorption and desorption measurements. ${ }^{36}$ The pore sizes were considered to be small in comparison to the wavelength of the incident light. This assumption was required to validate the use of the EMA in representing the optical response of sublayers consisting of glass, void, and water components. It was also assumed that the optical properties of the solid part of the leached layer are as those of the pristine ISG. This assumption was made due to the difficulty in accurately determining the refractive index of the solid part of a porous leached layer.

The pore sizes of sublayers, when it is possible, were calculated using the Kelvin equation (Eq. 4) describing the relationship between the relative 
humidity of vapor $\left(p / p_{o}\right)$ and the radius of a meniscus $\left(r_{m}\right)$ of the liquid in the pores. ${ }^{35}$

$$
\ln \frac{p}{p_{o}}=-\frac{1}{r_{m}} \frac{2 \gamma V_{L}}{R T} \cos \theta
$$

In Equation $4, \gamma$ and $V_{L}$ are the surface tension and molar volume of the liquid, respectively, while $R$ and $T$ are the gas constant and temperature. The contact angle between the pore wall and liquid is $\theta$. In this study, the pores were assumed to be cylindrical and $\theta$ was assumed to be $0^{\circ}$. The radius of a meniscus, based on those assumptions, is then equal to the pore radius $\left(r_{m}=r_{k}\right)$; the distribution of pore diameter $\left(2 r_{k}\right)$ is plotted in Fig. 6. The thickness of the physisorbed water layer in the pores cannot be determined and this study reports values of the pore diameter only. The surface tension and molar volume of water in the pores are impossible to be measured experimentally; thus, the values of bulk water were used in the calculations. The pore-size distribution is determined by taking the first derivative of water volume fraction versus the pore diameter $\left(\frac{\partial V_{\text {water }}}{\partial d_{\text {s }}}\right)$. The relative humidity-controlled SE experiment used to obtain adsorption/ desorption data for pore-size calculations is not very sensitive to pore diameters less than $2 \mathrm{~nm}^{35}$

\section{X-ray photoelectron spectroscopy}

XPS was used as a complementary technique to determine the thickness of alteration layer on corroded glass samples. The XPS depth profile measurements were performed with a Phi VersaProbe II spectrometer (Chanhassen, MN) that was equipped with a monochromatic $\mathrm{AlK}_{\alpha}$ $(1486.6 \mathrm{eV}) \mathrm{X}$-ray source and an Ar ion sputtering beam. The depth profiles of $\mathrm{O}, \mathrm{Na}, \mathrm{B}, \mathrm{Zr}$, and $\mathrm{Si}$ are given in the Supplementary Information.

\section{Time-of-Flight Secondary lon Mass Spectrometry}

The monolith sample corroded for 1625 days was analyzed using ToF-SIMS (IONTOF TOF 5). An O ion beam was set at $2 \mathrm{keV}$ and $510 \mathrm{nA}$ and used for surface abrasion $(200 \times 200 \mu \mathrm{m})$. Actual depth profile analysis was provided by a $\mathrm{Bi}$ ion sputtering beam $(25 \mathrm{keV}, 2 \mathrm{pA}, 30 \times 30 \mu \mathrm{m})$. The surface was neutralized during analysis by a low-energy electron flux $(<20 \mathrm{eV})$. Measuring the depth of the final crater allowed elemental profile depth calibration. $\mathrm{B}, \mathrm{Na}$, and $\mathrm{Ca}$ profiles were then normalized to the $\mathrm{Zr}$ profile to avoid matrix effects. Zr was chosen as it is immobile during glass alteration in these conditions. ${ }^{47}$ The resulting data were normalized to the mean measured in pristine glass to extract quantitative information.

\section{Data availability}

The data that support the findings of this study are available from the authors on reasonable request.

\section{ACKNOWLEDGEMENTS}

This work was supported as part of the Center for Performance and Design of Nuclear Waste Forms and Containers, an Energy Frontier Research Center funded by the U.S. Department of Energy, Office of Science, Basic Energy Sciences under Award \# DESC0016584. The authors thank Dr. Michael A. Hickner (The Pennsylvania State University) for the access to the spectroscopic ellipsometry setup in his lab.

\section{AUTHOR CONTRIBUTIONS}

The scope of the experiment was designed by D.N. and S.H.K. D.N. carried out SE analysis, H.L. conducted XPS depth profiling, M.C. and S.G. prepared 1625-day sample and performed ToF-SIMS depth profiling. N.S. and R.L.H. were involved in sample preparation and SE instrumentation, respectively. D.N., N.J.P., S.H.K. analyzed the SE data. D.N. and S.H.K. wrote the manuscript. All the authors helped on paper editing.

\section{ADDITIONAL INFORMATION}

Supplementary information accompanies the paper on the npj Materials Degradation website (https://doi.org/10.1038/s41529-018-0040-7).

Competing interests: The authors declare no competing interests.

Publisher's note: Springer Nature remains neutral with regard to jurisdictional claims in published maps and institutional affiliations.

\section{REFERENCES}

1. Frugier, P. et al. SON68 nuclear glass dissolution kinetics: current state of knowledge and basis of the new GRAAL model. J. Nucl. Mater. 380, 8-21 (2008).

2. Gin, S. et al. Nuclear glass durability: new insight into alteration layer properties. $J$. Phys. Chem. C. 115, 18696-18706 (2011).

3. Gin, S. et al. Atom-probe tomography, TEM and ToF-SIMS study of borosilicate glass alteration rim: a multiscale approach to investigating rate-limiting mechanisms. Geochim. Et. Cosmochim. Acta 202, 57-76 (2017).

4. Gin, S. et al. Origin and consequences of silicate glass passivation by surface layers. Nat. Commun. 6, 6360 (2015).

5. Gin, S. et al. The controversial role of inter-diffusion in glass alteration. Chem. Geol. 440, 115-123 (2016).

6. Godon, N., Gin, S., Rebiscoul, D. \& Frugier, P. SON68 glass alteration enhanced by magnetite. Procedia Earth Planet. Sci. 7, 300-303 (2013).

7. Nuclear Waste Glasses. How Durable? Elements 2, 357-364 (2006).

8. Vienna, J. D., Ryan, J. V., Gin, S. \& Inagaki, Y. Current understanding and remaining challenges in modeling long-term degradation of borosilicate nuclear waste glasses. Int. J. Appl. Glass Sci. 4, 283-294 (2013).

9. Frankel, G. S. et al. A comparative review of the aqueous corrosion of glasses, crystalline ceramics, and metals. npj Mater. Degrad. 2, 15 (2018).

10. Bunker, B. C. Molecular mechanisms for corrosion of silica and silicate glasses. J. Non-Cryst. Solids 179, 300-308 (1994).

11. Casey, W. H., Westrich, H. R., Banfield, J. F., Ferruzzi, G. \& Arnold, G. W. Leaching and reconstruction at the surfaces of dissolving chain-silicate minerals. Nature 366, 253 (1993).

12. Gin et al. Dynamics of self-reorganization explains passivation of silicate glasses. Nature Communications, https://doi.org/10.1038/s41467-018-04511-2 (2018).

13. Taschin, A., Bartolini, P., Marcelli, A., Righini, R. \& Torre, R. A comparative study on bulk and nanoconfined water by time-resolved optical Kerr effect spectroscopy. Faraday Discuss. 167, 293-308 (2013).

14. Indris, S., Heitjans, P., Behrens, H., Zorn, R. \& Frick, B. Fast dynamics of $\mathrm{H}_{2} \mathrm{O}$ in hydrous aluminosilicate glasses studied with quasielastic neutron scattering. Phys. Rev. B 71, 064205 (2005).

15. Collin, M. et al. Structure of international simple glass and properties of passivating layer formed in circumneutral $\mathrm{pH}$ conditions. npj Mater. Degrad. 2, 4 (2018).

16. Bourg, I. C. \& Steefel, C. I. Molecular dynamics simulations of water structure and diffusion in silica nanopores. J. Phys. Chem. C. 116, 11556-11564 (2012).

17. Ohkubo, T., Gin, S., Collin, M. \& Iwadate, Y. Molecular dynamics simulation of water confinement in disordered aluminosilicate subnanopores. Sci. Rep. 8, 3761 (2018).

18. Du, J. \& Rimsza, J. M. Atomistic computer simulations of water interactions and dissolution of inorganic glasses. npj Mater. Degrad. 1, 16 (2017).

19. Wongmanerod, C., Zangooie, S. \& Arwin, H. Determination of pore size distribution and surface area of thin porous silicon layers by spectroscopic ellipsometry. Appl. Surf. Sci. 172, 117-125 (2001).

20. Baklanov, M. R. et al. Porous structure of $\mathrm{SiO}_{2}$ films synthesized at low temperature and pressure. Thin Solid Films 171, 43-52 (1989).

21. Dultsev, F. \& Baklanov, M. Nondestructive determination of pore size distribution in thin films deposited on solid substrates. Electrochem. Solid State Lett. 2, 192-194 (1999).

22. Feldmann, M. \& Weißmann, R. Initial stages of float glass corrosion. J. Non-Cryst. Solids 218, 205-209 (1997).

23. Herino, R., Bomchil, G., Barla, K., Bertrand, C. \& Ginoux, J. L. Porosity and pore size distributions of porous silicon layers. J. Electrochem. Soc. 134, 1994-2000 (1987).

24. Kaspar, T. C., Reiser, J. T., Ryan, J. V. \& Wall, N. A. Non-destructive characterization of corroded glass surfaces by spectroscopic ellipsometry. J. Non-Cryst. Solids 481, 260-266 (2018).

25. Portal, S. \& Sempere, R. Study of alkali silicate glass corrosion using spectroscopic ellipsometry and secondary ion mass spectrometry. Phys. Chem. Glass. 44, 303-307 (2003).

26. Kushner, D. I. \& Hickner, M. A. Water sorption in electron-meam evaporated $\mathrm{SiO} 2$ on QCM crystals and its influence on polymer thin film hydration measurements. Langmuir 33, 5261-5268 (2017).

27. Gin, S. et al. An international initiative on long-term behavior of high-level nuclear waste glass. Mater. Today 16, 243-248 (2013).

28. Gin, S. et al. The fate of silicon during glass corrosion under alkaline conditions: a mechanistic and kinetic study with the international simple glass. Geochim. Et. Cosmochim. Acta 151, 68-85 (2015).

29. Aspnes, D. E., Theeten, J. B. \& Hottier, F. Investigation of effective-medium models of microscopic surface roughness by spectroscopic ellipsometry. Phys. Rev. B 20, 3292-3302 (1979).

30. Collin, M., Fournier, M., Charpentier, T., Moskura, M., \& Gin, S. Impact of alkali on the passivation of silicate glass. npj Mater. Degrad. 2, 16 (2018). 
31. Hsiao, E., Marino, M. J. \& Kim, S. H. Effects of gas adsorption isotherm and liquid contact angle on capillary force for sphere-on-flat and cone-on-flat geometries. J. Colloid Interface Sci. 352, 549-557 (2010).

32. Mamontov, E. \& Cole, D. R. Quasielastic neutron scattering study of dynamics of $\mathrm{CaCl}_{2}$ aqueous solution confined in Vycor glass. Phys. Chem. Chem. Phys. 8, 4908-4914 (2006).

33. Azam, M. S., Weeraman, C. N. \& Gibbs-Davis, J. M. Specific cation effects on the bimodal acid-base behavior of the silica/water interface. J. Phys. Chem. Lett. 3 1269-1274 (2012).

34. Yang, Z., Li, Q. \& Chou, K. C. Structures of water molecules at the interfaces of aqueous salt solutions and silica: cation effects. J. Phys. Chem. C. 113, 8201-8205 (2009).

35. Gregg, S. J. \& Sing, K. S. W. Adsorption, surface area, and porosity. (Academic Press, Cambridge, 1991).

36. Eslava, S. et al. Characterization of a molecular sieve coating using ellipsometric porosimetry. Langmuir 23, 12811-12816 (2007).

37. Banerjee, J., Bojan, V., Pantano, C. G. \& Kim, S. H. Effect of heat treatment on the surface chemical structure of glass: oxygen speciation from in situ XPS analysis. $J$. Am. Ceram. Soc. 101, 644-656 (2018).

38. Gin, S., Beaudoux, X., Angéli, F., Jégou, C. \& Godon, N. Effect of composition on the short-term and long-term dissolution rates of ten borosilicate glasses of increasing complexity from 3 to 30 oxides. J. Non-Cryst. Solids 358, 2559-2570 (2012).

39. Fournier, M., Gin, S. \& Frugier, P. Resumption of nuclear glass alteration: state of the art. J. Nucl. Mater. 448, 348-363 (2014).

40. Fournier, M., Gin, S., Frugier, P. \& Mercado-Depierre, S. Contribution of zeoliteseeded experiments to the understanding of resumption of glass alteration. $n p j$ Mater. Degrad. 1, 17 (2017).

41. Gin, S. Open scientific questions about nuclear glass corrosion. Procedia Mater. Sci. 7, 163-171 (2014).
42. Piovesan, V. et al. Chemical durability of peraluminous glasses for nuclear waste conditioning. npj Mater. Degrad. 2, 7 (2018)

43. Fujiwara, H. Spectroscopic ellipsometry: principles and applications. (Wiley, New Jersey, 2007).

44. Boissiere, C. et al. Porosity and mechanical properties of mesoporous thin films assessed by environmental ellipsometric porosimetry. Langmuir 21, 12362-12371 (2005).

45. Collins, R. W. \& Ferlauto, A. S. in Handbook of ellipsometry (ed Eugene A. Irene) 93-235 (William Andrew Publishing, Norwich, 2005).

46. Alterovitz, S. A. \& Johs, B. Multiple minima in the ellipsometric error function. Thin Solid Films 313-314, 124-127 (1998).

47. Cailleteau, C. et al. Insight into silicate-glass corrosion mechanisms. Nat. Mater. 7, 978 (2008).

Open Access This article is licensed under a Creative Commons Attribution 4.0 International License, which permits use, sharing, adaptation, distribution and reproduction in any medium or format, as long as you give appropriate credit to the original author(s) and the source, provide a link to the Creative Commons license, and indicate if changes were made. The images or other third party material in this article are included in the article's Creative Commons license, unless indicated otherwise in a credit line to the material. If material is not included in the article's Creative Commons license and your intended use is not permitted by statutory regulation or exceeds the permitted use, you will need to obtain permission directly from the copyright holder. To view a copy of this license, visit http://creativecommons. org/licenses/by/4.0/.

(c) The Author(s) 2018 